\title{
Deletion of IFT20 in early stage T Iymphocyte differentiation inhibits the development of collagen-induced arthritis
}

\author{
Xue Yuan ${ }^{1}$, Lee Ann Garrett-Sinha ${ }^{2}$, Debanjan Sarkar ${ }^{3}$ and Shuying Yang ${ }^{1,4}$
}

IFT20 is the smallest member of the intraflagellar transport protein (IFT) complex B. It is involved in cilia formation. Studies of IFT20 have been confined to ciliated cells. Recently, IFT20 was found to be also expressed in non-ciliated $\mathrm{T}$ cells and have functions in immune synapse formation and signaling in vitro. However, how IFT20 regulates T-cell development and activation in vivo is still unknown. We deleted the IFT20 gene in early and later stages of T-cell development by crossing IFT20 flox/flox $($ IFT20 f/f $)$ mice with Lck-Cre and CD4-Cre transgenic mice, and investigated the role of IFT20 in T-cell maturation and in the development of T cell-mediated collagen-induced arthritis (CIA). We found that both $L c k-C r e / I F T 20^{f / f}$ and CD4-Cre/IFT20 f/f mice were indistinguishable from their wild-type littermates in body size, as well as in the morphology and weight of the spleen and thymus. However, the number of CD4- and CD8-positive cells was significantly lower in thymus and spleen in $L c k-C r e / I F T 20^{f / f}$ mice. Meanwhile, the incidence and severity of CIA symptoms were significantly decreased, and inflammation in the paw was significantly inhibited in Lck-Cre/IFT20 f/f mice compared to $\mathrm{Lck}$-Cre/IFT20 ${ }^{+/+}$littermates. Deletion IFT20 in more mature T cells of CD4-Cre/IFT20 ${ }^{f / f}$ mice had

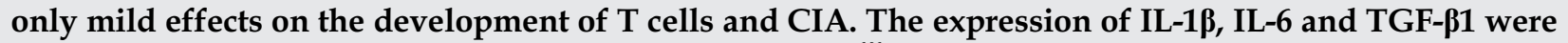
significantly downregulated in the paw of $L c k-C r e / I F T 20^{f / f}$ mice, but just slight decreased in CD4-Cre/IFT20 f/f mice. These results demonstrate that deletion of IFT20 in the early stage of T-cell development inhibited CIA development through regulating $\mathrm{T}$-cell development and the expression of critical cytokines.

Bone Research (2014) 2, 14038; doi:10.1038/boneres.2014.38; Published online: 18 November 2014

\section{INTRODUCTION}

Intraflagellar transport (IFT) proteins are a group of proteins which were first found to be essential for cilia formation. ${ }^{1-2}$ So far, 20 IFT proteins have been identified. These proteins form intraflagellar transport complex A (IFT-A) and complex B (IFT-B). ${ }^{3}$ IFT-A contains six proteins (IFT144, IFT140, IFT139, IFT122, IFT121 and IFT43) ${ }^{4-6}$ and IFT-B contains fourteen proteins (IFT20, IFT22, IFT25, IFT27, IFT46, IFT52, IFT54, IFT57, IFT70, IFT74/IFT72, IFT80, IFT81, IFT88 and IFT172). ${ }^{4,6-8}$ IFT proteins cooperate with IFT motors (kinesin and dynein) to drive macromolecules from the base to the tip of the cilium (anterograde transport) and from the tip of the cilium back to the cell body (retrograde transport). ${ }^{9}$

IFT2O is the smallest of the IFT complex B proteins, and has several unique features. IFT2O is anchored to the Golgi complex by Golgin protein, i.e., Golgi Microtubule
Associated Protein 210/thyroid hormone receptor interacting protein 11. IFT20 is involved in ciliary protein sorting, ${ }^{10-11}$ and also exhibits strong interactions with IFT57/ Hippi and kinesin II subunit Kif3b, indicating its role in IFT complex and motor assembly. ${ }^{12}$ Hematopoietic stem cells have been believed to lack of IFT protein related signaling due to lack cilia. ${ }^{13}$ Recently, however, a breakthrough discovery was made by Finetti et al. ${ }^{14}$ showing that IFT20 is expressed in lymphoid and myeloid cells, indicating that IFT20 has functions independent of cilia formation. They demonstrated that IFT20 is involved in the polarized recycling of the T-cell receptor (TCR)/CD3 complex, which connects IFT with membrane trafficking. ${ }^{14}$ When antigenpresenting cells present antigens to T cells, IFT20 promotes polarized recycling and clustering of the TCR at the immune synapse. Knockdown of IFT20 in T cells blocks both

\footnotetext{
'Department of Oral Biology, School of Dental Medicine, University at Buffalo, The State University of New York, Buffalo, NY 14214, USA;

${ }^{2}$ Department of Biochemistry, School of Medicine and Biomedical Sciences, University at Buffalo, The State University of New York, Buffalo, NY

14203, USA; ${ }^{3}$ Laboratory for Biomaterials and Regenerative Therapeutics, Department of Biomedical Engineering, University at Buffalo, The State University of New York, Buffalo, NY 14260-2050, USA and ${ }^{4}$ Developmental Genomics Group, New York State Center of Excellence in Bioinformatics and Life Sciences, University at Buffalo, The State University of New York, Buffalo, NY 14203, USA

Correspondence: SY Yang (sy47@buffalo.edu)

Received: 6 May 2014; Revised: 26 September 2014; Accepted: 28 September 2014
} 
constitutive TCR recycling and the polarization of TCR recycling to the immune synapse. ${ }^{14}$ These novel findings demonstrated that IFT2O is a regulator of immune synapse assembly in T cells in vitro. However, how IFT20 regulates T cell development and function in vivo is largely unknown.

A mouse IFT20 floxed allele (IFT20 $0^{f / f}$ ) has been described by Jonassen et al. ${ }^{15}$ Germline deletion of IFT20 with PrmCre causes embryonic lethality. ${ }^{15}$ So far, only HoxB7-Cre and human red/green pigment gene promoter-Cre have been used to study the role of IFT20 in kidney and photoreceptor cells. ${ }^{15-16}$ In order to study the role of IFT2O in T cells in vivo, we deleted IFT20 in early and later stages of T-cell development by crossing IFT20 $\mathrm{O}^{f / f}$ mice with Lck-Cre or CD4Cre transgenic mice, respectively, to generate T cell-specific IFT20 knockout mouse models.

Rheumatoid arthritis (RA) is a systemic autoimmune disease accompanied by synovial inflammation and destruction of joints. ${ }^{17}$ In order to uncover the pathogenesis of RA, several arthritis mouse models have been established, including collagen-induced arthritis (CIA), antigen-induced arthritis, collagen antibody-induced arthritis and TNF- $\alpha$ transgenic mouse model of inflammatory arthritis. ${ }^{18-20} \mathrm{CIA}$ is the most widely used experimental model of RA and recently has been extensively studied to identify the pathogenic mechanism of RA and to examine the effects of therapeutics. Type II collagen is exclusively expressed in the articular cartilage. Autoimmune response to type II collagen offers a validated mechanism by which the immune system contributes to the pathogenesis of RA in human patients. Therefore, the mouse CIA model shares both immunological and pathological features with human RA. Although both T cell- and B cell-specific responses to type II collagen contribute to immunopathogenesis of CIA, T cells are known to play critical roles in CIA initiation and disease perpetuation. ${ }^{21}$ Defects in T cells have been shown to block the CIA initiation and development in mouse models. ${ }^{22-24}$

Considering the potential role of IFT2O in TCR/CD3 recycling during T-cell activation, it is interesting to investigate whether deletion of IFT20 in the T-cell lineage affects CIA initiation and development. In this study, we challenged Lck-Cre/IFT2O f/f and CD4-Cre/IFT20 f/f mice with type ॥ chicken collagen and analyzed CIA pathogenesis. We explored the role of IFT20 in T cells in vivo by comparing the incidence and the intensity of CIA in Lck-Cre/IFT2 $0^{f / f}$ and CD4-Cre/IFT2O f/f mice with their wild-type littermates. Our results demonstrate that specific deletion of IFT20 in T cells with Lck-Cre or CD4-Cre did not lead to any gross changes in phenotypes such as body weight or the morphology and weight of spleen and thymus. However, specific deletion of IFT2O at an early stage of T-cell differentiation with Lck-Cre significantly reduced CD4and CD8-positive cells in both the thymus and spleen. Additionally, these mice showed significantly reduced incidence and severity of CIA. Unexpectedly, deletion of IFT20 with CD4-Cre showed minor effect on CD4- and CD8positive cell population and CIA development. This data suggests the complicated role of IFT20 in T-cell development and activation.

\section{MATERIALS AND METHODS}

Mice

IFT2 ${ }^{f / f}$ mice, Lck-Cre mice, and CD4-Cre mice were all purchased from the Jackson Laboratory (Bar Harbor, ME, USA). IFT2 ${ }^{f / f}$ mice have been previously described. ${ }^{25}$ Mice carrying the IFT $20^{\text {flox }}$ allele were crossed with Lck-Cre mice or CD4-Cre mice in order to delete exons 2 and 3 and create Lck-Cre/IFT2O $0^{f / f}$ and CD4-Cre/IFT20 f/f mice. Homozygous Lck-Cre/IFT2O ${ }^{f / f}$ and CD4-Cre/IFT2O/ff mice are viable. Mouse genotyping was done by polymerase chain reaction (PCR) of proteinase K-digested toe DNA as we have previously described ${ }^{26}$ by using two primers IFT2OF (5'-ACT CAG TAT GCA GCC CAG GT-3') and IFT2OR (5'-GCT AGA TGC TGG CGT AAA G-3'), which yielded a 506 bp band for the flox allele and a 404 bp band for wild-type allele. ${ }^{25}$ The presence of the Lck-Cre and CD4-Cre transgene was detected with the following primers CREF (5'-CCT GGA AAA TGC TTC TGT CCG TTT GCC-3') and CREB (5'-GGC GCG GCA ACA CCA TTT T-3'), which generated a PCR product of $550 \mathrm{bp}$. Mouse studies were approved by University at Buffalo Institutional Animal Care and Use Committee.

Isolation of T cells from spleen

T cells were isolated from total spleen cells of Lck-Cre/ IFT2O $^{+/+}$, LCk-Cre/IFT2O ${ }^{f / f}$, CD4-Cre/IFT20 ${ }^{f / f}$ and CD4-Cre/ IFT20 $0^{f / f}$ mice using a pan T-cell isolation kit (mouse; Miltenyi Biotec Inc., Auburn, CA, USA) following the manufacturer's instruction. T cells and non-T cells were used for IFT20 expression analysis by quantitative real-time polymerase chain reaction ( $\mathrm{PPCR}$ ).

Flow cytometry

Spleen and thymus were harvested from Lck-Cre//FT20 ${ }^{+/+}$, Lck-Cre/IFT2O ${ }^{f / f}$, CD4-Cre/IFT20 ${ }^{f / f}$ and CD4-Cre/IFT20 ${ }^{f / f}$ mice. Single cell suspensions were prepared by crushing the spleen or thymus, followed by passing through an 18.5 gauge needle three times. The cells were resuspended in $0.2 \%$ BSA-PBS and exposed to Fc block (anti-CD 16/32; BD Pharmingen) for $15 \mathrm{~min}$. Then, PE tagged anti-CD4 (553652; BD Pharmingen) and antigen-presenting cell-tagged antiCD8 (553035; BD Pharmingen) were added. After $20 \mathrm{~min}$ incubation in the dark, the cells were washed and processed using a BD LSRFortessa flow cytometry machine.

Collagen-induced arthritis

CIA was induced following the protocol from Chondrex (Redmond, WA, USA). In brief, mice were immunized with 
$100 \mu \mathrm{L}$ of $2 \mathrm{mg} \cdot \mathrm{mL}^{-1}$ chicken type $\|$ collagen (Cat. No. 20012; Chondrex) emulsified in Complete Freund's Adjuvant (CFA, Cat. No. 7023; Chondrex) containing $5 \mathrm{mg} \cdot \mathrm{mL}^{-1} \mathrm{M}$. tuberculosis intradermally at the base of the tail on day 0 . On day 21 , the mice were given booster injection with the same amount of chicken type Il collagen and CFA intradermally at the base of the tail. ${ }^{18}$

Evaluation of arthritis severity

To quantitatively evaluate the severity of the arthritis, an arthritis score was evaluated every 3 days for as long as 66 days after the first immunization. Inflammation of the four paws was assessed by using the following scale from 0 to 4 : grade 0, normal; grade 1, slight redness and swelling of the ankle or wrist; grade 2, moderate redness and swelling of ankle or wrist; grade 3, extensive redness and swelling of the entire paw including digits; grade 4, maximally inflamed limb with involvement of multiple joints showing joint distortion and/or rigidity. The maximum score per mouse was 16. Mouse with clinical score greater than 4 was given a diagnosis of arthritis. The mean arthritic score was determined in arthritic animals only. ${ }^{27-29}$

Paw thickness measurement

The thickness of hind paws was measured using Precision Vernier Calipers (General, New York, NY, USA) and recorded 60 days after first immunization. ${ }^{30}$

Histological assessment of arthritis

For histological analysis, mice were sacrificed at day 66 after the first immunization. Hind paws were collected and fixed in $10 \%$ neutral formalin, decalcified with 10\% EDTA for 1 week and embedded in paraffin. Then, $5-\mu \mathrm{m}$ slices were prepared and stained with hematoxylin and eosin. ${ }^{2}$ The joint sections were graded for disease severity using a scoring system from 0 to $4:{ }^{31-32}$ grade 0 , normal ankle joint; grade 1, normal synovium with few mononuclear cells; grade 2, a few layers of flat to rounded synovial lining cells and dense infiltration with mononuclear cells; grade 3, hyperplasia of the synovium with mononuclear cells infiltration; and grade 4, severe synovitis with pannus and articular cartilage destruction.

Thymus and spleen assays

Thymus and spleen were removed and weighed immediately after mice were killed at the end of the experiments. The thymus index was calculated as the ratio of thymus weight to mouse body weight $\left(\mathrm{mg} \cdot \mathrm{g}^{-1}\right)$ and the spleen index was calculated as the ratio of spleen weight to mouse body weight $\left(\mathrm{mg} \cdot \mathrm{g}^{-1}\right) .^{28,33}$

QPCR

Paws were quickly frozen in liquid nitrogen and ground with Trizol reagent using a chilled mortar and pestle for quality RNA isolation (Invitrogen, Carlsbad, CA, USA), following the manufacturer's instructions. CDNA was synthesized from $2 \mu \mathrm{g}$ total RNA using RNA to CDNA EcoDry Premix kit (Clontech, Palo Alto, CA, USA). GPCR was performed with $A B I$ PRISM 7500 real time PCR system (Invitrogen) using SYBR Green PCR master Mix (Invitrogen). Sequences and product lengths for each primer pair were as follows: IFT20 (forward: 5'-AGA AGC AGA GAA CGA GAA GAT G-3'; reverse: 5'-CAC AAA GCT TCA TAT TCA ACC CG-3', 156 bp); IL-1 $\beta$ (forward: 5'-ACA GAT GAA GTG CTC CTT CCA-3'; reverse: 5'-GTC GGA GAT TCG TAG CTG GAT-3', 73 bp); ;4 IL-6 (forward: 5'-ATG GAT GCT ACC AAA CTG GAT-3'; reverse: 5'-TGA AGG ACT CTG GCT TTG TCT-3', 139 bp) ${ }^{35}$ and TGF- $\beta$ (forward: 5'-TGA CGT CAC TGG AGT TGT ACG G-3'; reverse: 5'-GGT TCA TGT CAG GAT GGT GC-3', $170 \mathrm{bp}) .{ }^{36}$ All of the reactions were run in triplicate and normalized to the housekeeping gene GAPDH.

\section{Statistical analysis}

All data were represented as mean \pm standard deviation (s.d.). Differences between groups were evaluated by unpaired, two-tailed Student's t-test. $P$ values less than 0.05 were considered to be significant.

\section{RESULTS}

Deletion of IFT20 in different stages of T-cell development showed normal Mendelian genetics and normal phenotypes To investigate the roles of IFT20 in T cells, we generated T cell-specific IFT20 knockout mice, as described in the section on 'Materials and methods'. Mice harboring loxP sites flanking the second and third exons of IFT20 gene (IFT20 $0^{f / f}$ ) were crossed with Lck-Cre or CD4-Cre transgenic mice (Figure 1a). Cre recombinase-mediated deletion removed the start codon and 71 of 132 codons of IFT20 gene and produced a null mutant allele. ${ }^{25}$ Genotyping of mice was performed by PCR analysis (Figure 1b). The bands of 506 bp represent the IFT2 $0^{\text {flox }}$ allele while the bands of $404 \mathrm{bp}$ represent the wild-type allele $\left(\right.$ IFT $\left.20^{+}\right)$. The $550 \mathrm{bp}$ bands indicate that the Cre gene is present allowing Cremediated deletion the target gene. Both Lck-Cre and CD4-Cre transgenic lines are T cell-specific targeted Cre, which are known to delete target genes at early and later stages of thymocyte differentiation (Figure 1a). Doublenegative (DN, $\mathrm{CD} 4^{-} \mathrm{CD} 8^{-}$) thymocytes go through four developmental stages (DN1 to DN4), which are distinguishable by their surface markers. ${ }^{37}$ Lck promoter activity is first detected at the DN2 stage, ${ }^{38}$ and the Lck-Cre transgene is expressed during early intrathymic development in the thymus. ${ }^{38-39} \mathrm{CD} 4$ is first expressed in the $\mathrm{CD} 4^{+} \mathrm{CD} 8^{+}$doublepositive (DP) thymocyte stage and, therefore, the CD4-Cre transgene is not expressed until a later stage of thymic 


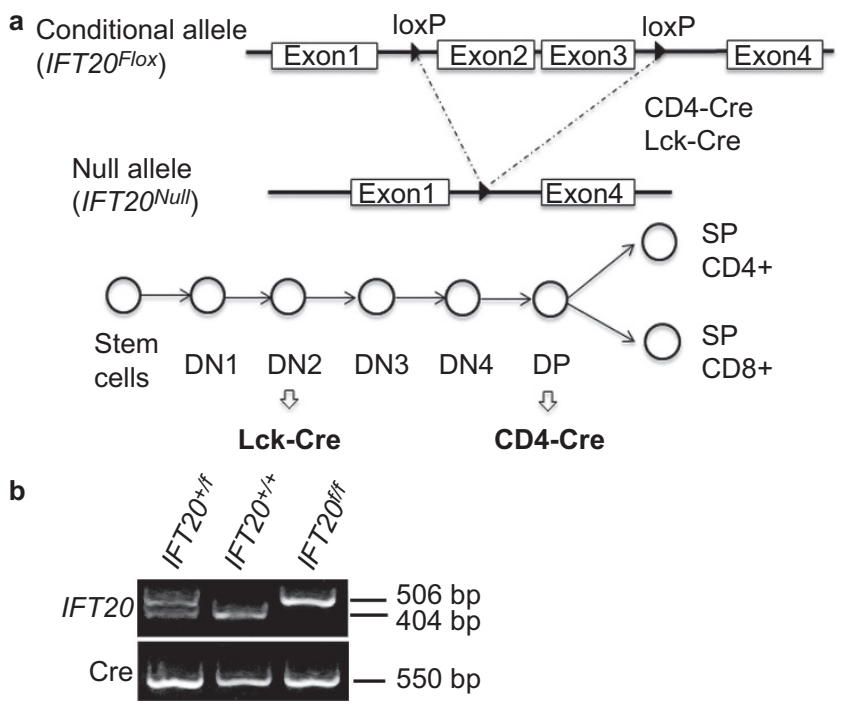

C
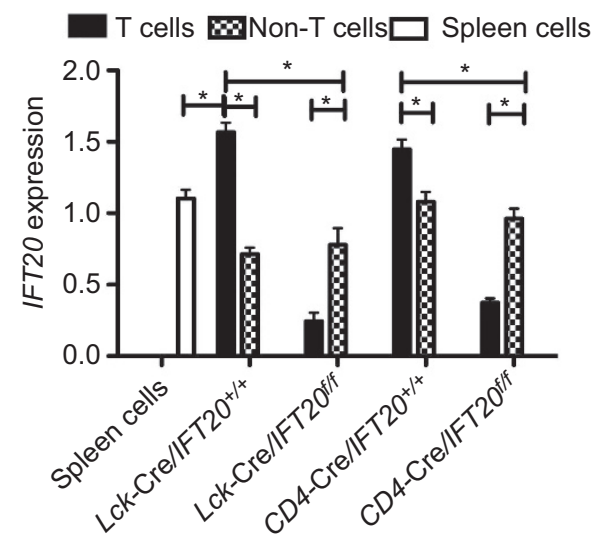

Figure 1. Deletion of IFT20 in different stages of T-cell development showed normal Mendelian genetics and normal phenotypes. (a) Structure of IFT2 $20^{f l o x}$ and IFT $20^{\text {Null }}$ alleles. Two loxP sites were inserted into IFT20 locus flanking exon2 and exon3. Lck-Cre or CD4-Cre mediated the excision of exons 2 and 3 and converted IFT2 flox to IFT2 ${ }^{\text {Null }}$. Lck-Cre and CD4-Cre are T cell-specific Cre transgenes driven either by Lck or CD4 promoter. The stages of thymocyte differentiation where the proximal Lck and CD4 promoters are active are indicated. DN: double negative; DP: double positive. (b) Genotyping showed wild-type and conditional alleles as well as the Cre recombinase transgene. The sequence of primers is given in the section on 'Materials and methods'. (c) qPCR analysis shows less IFT20 mRNA expression in T cells from Lck-Cre/IFT20/f and CD4-Cre/IFT20 f/f spleen. The expression of IFT20 was normalized to GAPDH expression ( ${ }^{*} P<0.001$ versus controls). Spleen cells: spleen cells from wild-type mouse; T cells: sorted T cells from spleen; non-T cells: other cells in spleen.

development. ${ }^{38}$ To detect the IFT20 deletion in T cells, total $\mathrm{T}$ cells were harvested from the spleen of Lck-Cre/ $\mathrm{IFT}^{+1+} \mathrm{I}^{+}$, Lck-Cre/IFT20 f/f, CD4-Cre/IFT20 f/f and CD4-Cre/ $\mathrm{IFT}_{20} \mathrm{I}^{++}$mice using the pan T-cell isolation kit. T cells were negatively selected and lysed with Trizol. Non-T cells were also harvested and used as a control. In mice without Cre, expression of IFT20 was about 1.5- to 2-fold higher in the T-cell population than the non-T-cell population of a

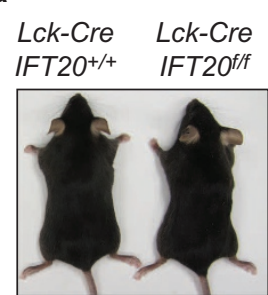

c

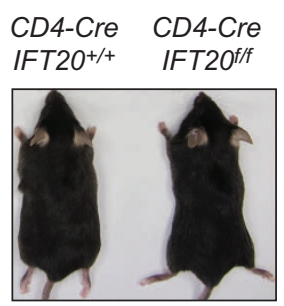

b

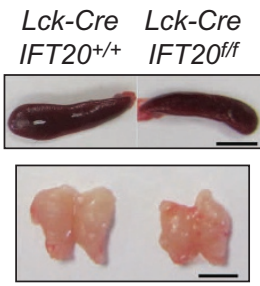

d
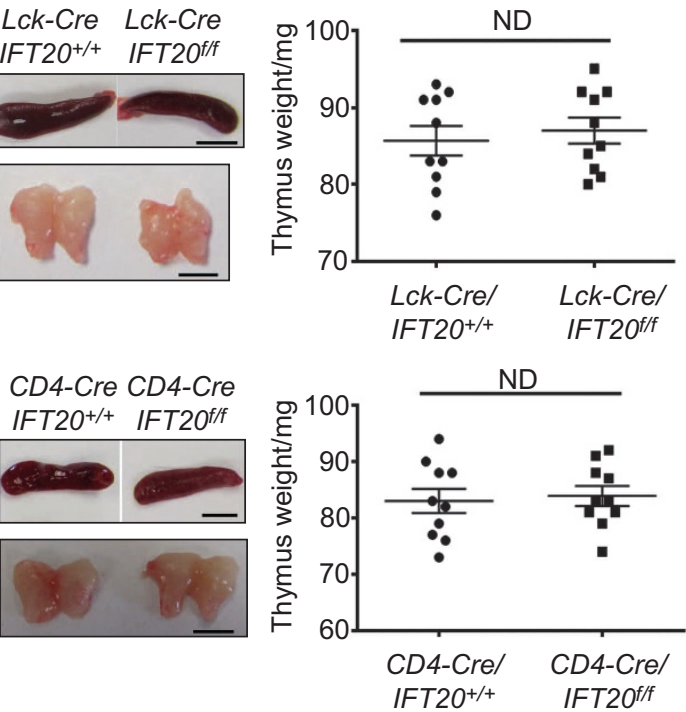
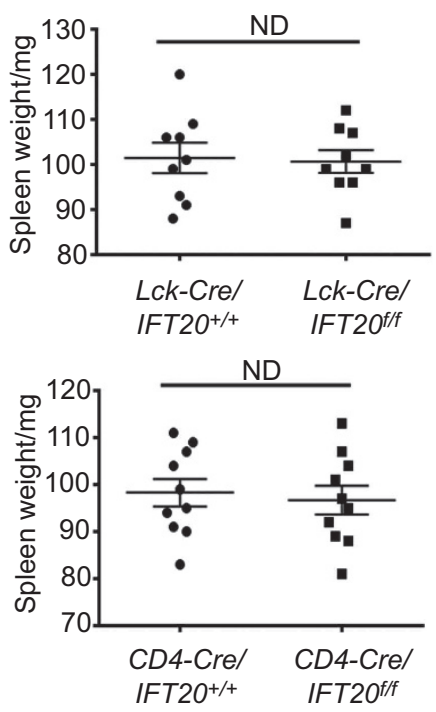

Figure 2. Both $L c k$-Cre/IFT2 $0^{f f f}$ and CD4-Cre/IFT20/f mice were indistinguishable from wild-type littermates in mouse body size, and in the morphology and weights of the spleen and thymus. (a) Representative photograph of $L c k$-Cre/IFT20 $0^{+/+}$and $L c k$-Cre/IFT2 $0^{f / f}$ mice at 3 months of age showing similar body mass and appearance. (b) Thymus and spleen from Lck-Cre/IFT20f/f mice shown next to those from a $L c k$-Cre/IFT20 ${ }^{+/+}$littermate. Similar $L c k$-Cre/ $I F T 20^{f / f}$ thymic weight was found compared to age-matched $L c k$-Cre/IFT20 ${ }^{+/+}(n=10, P>0.05)$ (c) Representative photograph of CD4-Cre/IFT20 $0^{+/+}$and $\mathrm{CD} 4-\mathrm{Cr} / \mathrm{IFT} 20^{f / f}$ mice at 3 months of age showing similar body mass and appearance. (d) Thymus and spleen from CD4-Cre/IFT2 $0^{f / f}$ mice shown next to those from a CD4-Cre/IFT2 $0^{+/+}$littermate. Similar Lck-Cre/IFT20 f/f thymic weight was observed compared to CD4-Cre/IFT20 ${ }^{+/+}$littermate $(n=10$, $P>0.05)$ ND, no significant difference. 
the spleen (Figure 1c). This suggests that $\mathrm{T}$ cells express more IFT20 than do non-T cells in the spleen (which comprise in large part B cells) and supports the idea that IFT20 may play a special role in T-cell development. IFT20 expression was significantly reduced (5- to 10-fold) in the T cells of Lck-Cre/IFT2 ${ }^{f / f}$ mice compared to that in the T cells from Lck-Cre/IFT20 f/f mice (Figure 1c). IFT20 expression was also significantly reduced in the T cells of CD4-Cre/ IFT2 $0^{f / f}$ mice compared to that in the T cells from CD4Cre/IFT20 $0^{+/+}$mice. However, IFT20 expression in T cells from $\mathrm{CD} 4-\mathrm{Cre} / \mathrm{IFT} 2 \mathrm{O}^{f / f}$ mouse was slightly (but not significantly) higher than that from Lck-Cre/IFT20 f/f .

Lck-Cre/IFT2O $0^{f / f}$ and CD4-Cre/IFT2O ${ }^{f / f}$ mice were born at normal Mendelian ratios and appeared normal (Figure $2 a$ and 2c). Further analysis of spleen and thymus weights did not reveal any abnormalities. The spleens and thymuses in LckCre/IFT20 f/f and CD4-Cre/IFT20 f/f mice have similar weights compared to wild-type control littermates (Figure $2 \mathrm{~b}$ and $2 \mathrm{~d}$ ).
Deletion of IFT2O in an early stage of T-cell differentiation reduced the population of CD4- and CD8-positive cells To investigate the role of IFT20 in T-cell development, we detected the CD4- and CD8-positive cells in both thymus and spleen with flow cytometry. As shown in Figure $3 a$ and $3 \mathrm{~b}$, depletion of IFT20 in the beginning of DP stage with LckCre resulted in a significant loss of $\mathrm{CD}^{+}, \mathrm{CD}^{+}$and $\mathrm{CD} 4^{+} \mathrm{CD} 8^{+} \mathrm{T}$ cells in the spleen, while it increased the $\mathrm{CD} 4^{-} \mathrm{CD} 8^{-}$population. In the thymus, the $\mathrm{CD} 4^{+}$and $\mathrm{CD}^{+} \mathrm{T}$ cells were also significantly reduced, accompanied by increased $\mathrm{CD} 4^{-} \mathrm{CD} 8^{-}$cell numbers. However, the numbers of CD4 and CD8 single- and double-positive T cells were not apparently affected when IFT20 was deleted with CD4-Cre (Figure $3 \mathrm{c}$ and $3 \mathrm{~d}$ ), indicating that the loss of IFT20 in DP stage does not significantly alter thymocyte differentiation. These findings suggest that IFT20 may function in DN proliferation, but is not required for further differentiation. a
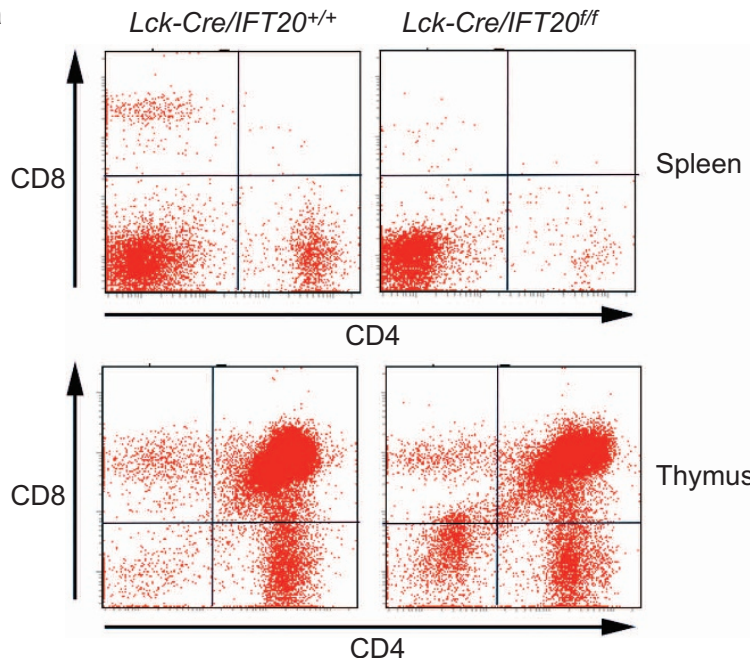

b

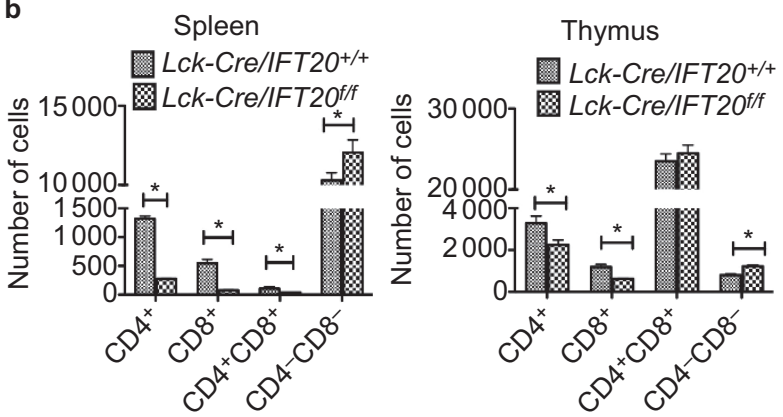

C
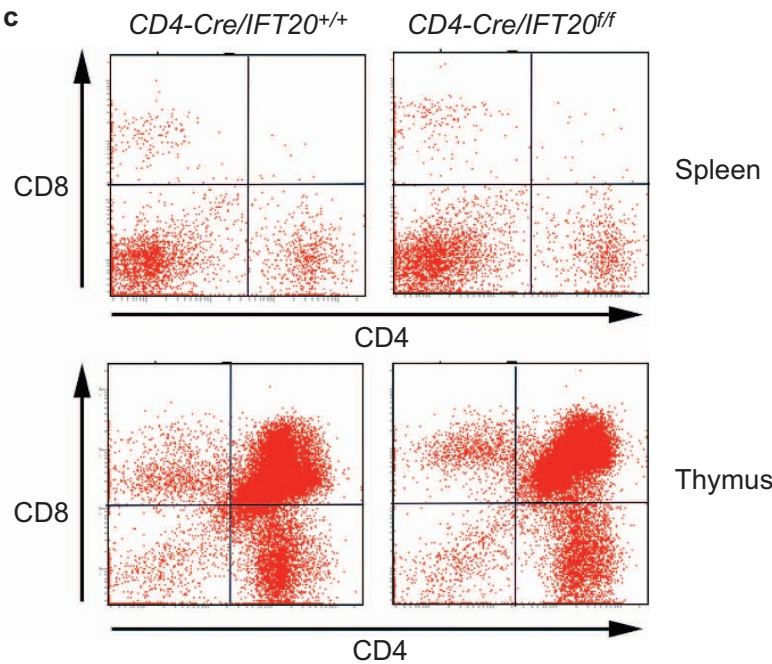

d

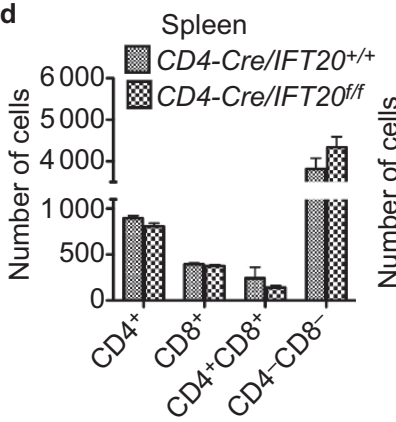

Thymus CD4-Cre/IFT20+/+ CD4-Cre/IFT2Of/f

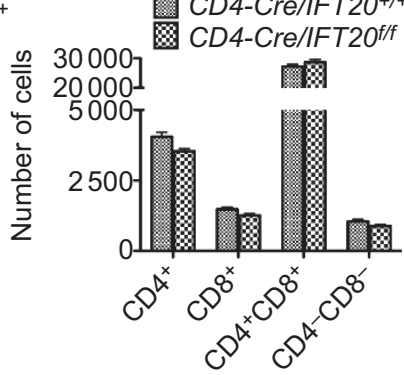

Figure 3. Deletion IFT20 in double-negative thymocytes affected the T-cell development. (a) Thymuses and spleens were collected from 1-month-old Lck-Cre/IFT $20^{+/+}$and Lck-Cre/IFT20/f mice; the cells were analyzed by flow cytometry for CD4 and CD8 expression. In the flow cytometry pictures: top left represents $\mathrm{CD} 8^{+} \mathrm{CD} 4^{-}$cells; top right represents $\mathrm{CD} 8^{+} \mathrm{CD} 4^{+}$cells; bottom left represents $\mathrm{CD} 8^{-} \mathrm{CD} 4^{-}$cells; and bottom right represents $\mathrm{CD}^{-} \mathrm{CD} 4^{+}$cells. (b) Number of $\mathrm{CD} 4$ single-positive $\left(\mathrm{CD} 4^{+}\right), \mathrm{CD} 8$ single-positive $\left(\mathrm{CD} 8^{+}\right), \mathrm{CD} 4$ and $\mathrm{CD} 8$ double-positive $\left(\mathrm{CD} 4^{+} \mathrm{CD} 8^{+}\right)$, and $\mathrm{CD} 4$ and CD8 double-negative $\left(\mathrm{CD} 4{ }^{-} \mathrm{CD} 8^{-}\right)(n=4, * P<0.01)$. (c) Flow cytometry of cells from thymuses and spleens of $\mathrm{CD} 4-\mathrm{Cr} / \mathrm{IFT20^{+/+ }}$ and $\mathrm{CD} 4-\mathrm{Cre} /$ IFT2 $0^{f / f}$ mice. (d) Number of CD4 single-positive $\left(\mathrm{CD} 4^{+}\right), \mathrm{CD} 8$ single-positive $\left(\mathrm{CD} 8^{+}\right), \mathrm{CD} 4$ and CD8 double-positive $\left(\mathrm{CD} 4^{+} \mathrm{CD} 8^{+}\right)$and $\mathrm{CD} 4$ and $\mathrm{CD} 8$ double-negative $\left(\mathrm{CD}^{-} \mathrm{CD}^{-}\right)(n=4)$. 


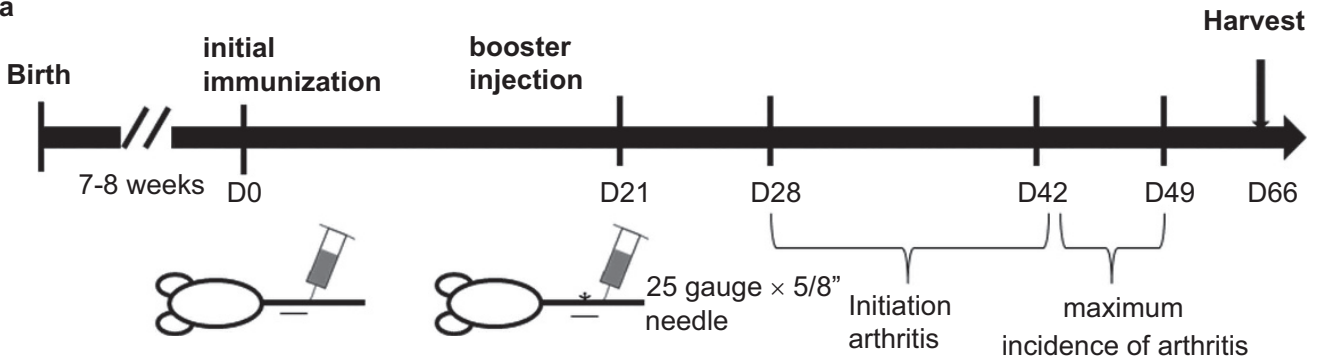

b

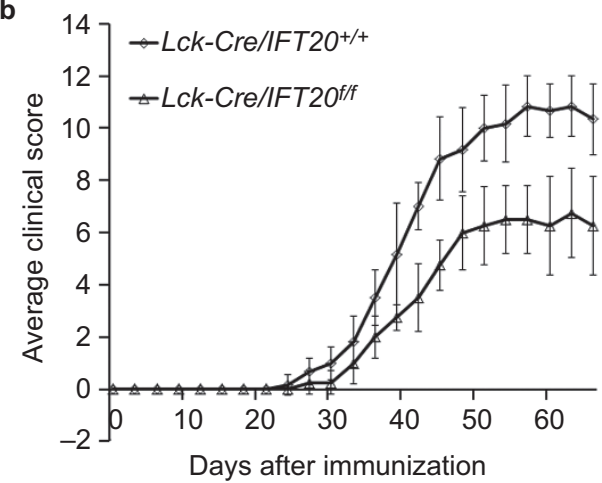

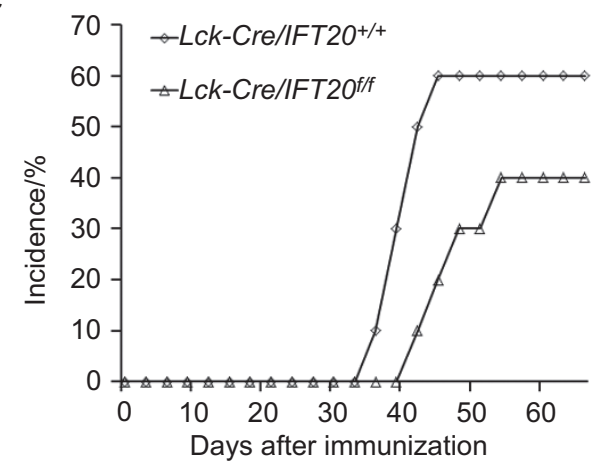

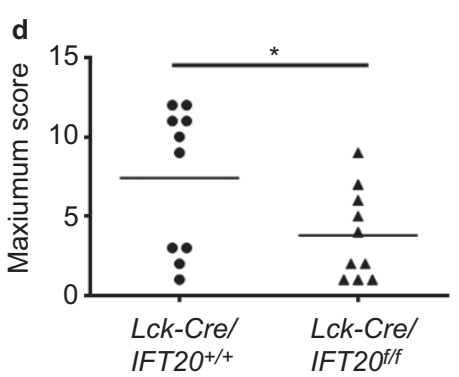

e

f
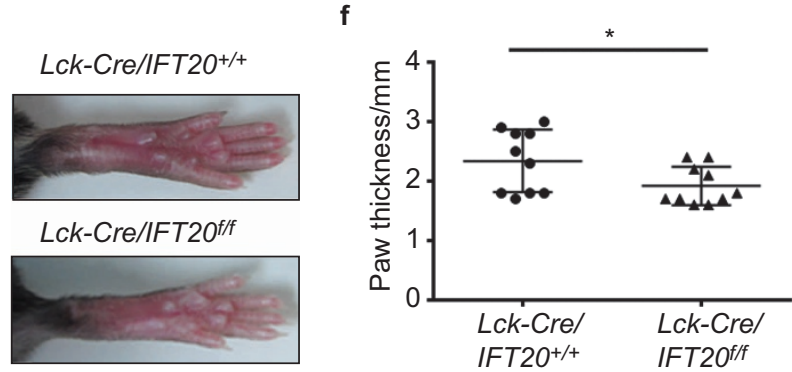

Figure 4. Deletion IFT20 in double-negative thymocytes affected the development of CIA. (a) Timeline for the CIA mouse model. Seven- to eight-weekold mice were immunized with $100 \mu \mathrm{L}$ emulsion containing equal volume of CFA (including $5 \mathrm{mg} \cdot \mathrm{mL}^{-1}$ of $M$. tuberculosis) and chicken type II collagen solution $\left(2 \mathrm{mg} \cdot \mathrm{mL}^{-1}\right.$ in $0.05 \mathrm{~mol} \cdot \mathrm{mL}^{-1}$ acetic acid). The booster injection (Insert site: $3 \mathrm{~cm}$ from the base of the tail Injection site: $1.5 \mathrm{~cm}$ from the base) was made with the same emulsions 21 days after initial injection (Insert site: $2 \mathrm{~cm}$ from the base of the tail Injection site: $0.5 \mathrm{~cm}$ from the base). Arthritis usually can be observed 4-6 weeks after the first immunization with the maximum incidence of arthritis at 6-7 weeks. All the experimental mice were harvested at day 66 for the histological analysis. (b) Mean clinical scores \pm s.d. of arthritis in $L c k-C r e / I F T 20^{+/+}(n=6)$ and Lck-Cre/IFT2 $0^{f / f}$ mice $(n=4)$ with arthritis $(P<0.01$ after day 40$)$. (c) Percentage of mice of $L c k-C r e / I F T 20^{+/+}$and $L c k$-Cre/IFT2 $0^{f / f}$ mice that developed arthritis $(n=10, P<0.05$ after day 40$)$. (d) The maximum clinical score was recorded until day $66(n=10, * P<0.01)$. (e) Hind paws of type II collagen immunized $L c k-C r e / I F T 20^{+/+}$and $L c k$-Cre/ IFT2 $0^{f / f}$ mice. (f) The hind paw thickness was measured at day 66 to indicate arthritis development $(n=10, * P<0.01)$.

Deletion of IFT20 at an early stage of T-cell differentiation suppressed the development of CIA

To determine the functional role of IFT20 in T cell-mediated inflammatory diseases, we created the CIA model in wildtype and IFT20 mutant mice. The C57/BL6 strain has been considered to be a CIA-resistant strain, due to little or no incidence of $\mathrm{ClA}$ upon immunization. ${ }^{18,40}$ However, Campbell et al $^{27}{ }^{27}$ successfully induced arthritis at relatively high incidence in ClA-resistant mouse strains, such as C57BL/ 6. C57BL/10, and 129/Sv mice (H-2b) with CFA, which contains $5 \mathrm{mg} \cdot \mathrm{mL}^{-1}$ of $\mathrm{M}$. tuberculosis. We used this CIA model with a slight modification, and the immunization schedule followed is shown in Figure 4a. Six- to seven-week-old, agematched Lck-Cre/IFT2O ${ }^{+/+}$and Lck-Cre/IFT20 f/f C57BL/6 mice were chosen for generating the CIA model. Stable emulsions with an equal volume of CFA (containing $5 \mathrm{mg} \cdot \mathrm{mL}^{-1}$ of $M$. tuberculosis) and chicken type II collagen solution (2 $\mathrm{mg} \cdot \mathrm{mL}^{-1}$ in $0.05 \mathrm{~mol} \cdot \mathrm{mL}^{-1}$ acetic acid) were prepared immediately before the injection on day 0 (initial immunization) and day 21 (booster injection). Each mouse received an accurate $0.1 \mathrm{~mL}$ of the emulsion each time. For the initial immunization, the injection site was $2 \mathrm{~cm}$ from the base of the tail, and a 25 gauge $\times 5 / 8^{\prime \prime}$ needle was used to reach to $0.5 \mathrm{~cm}$ from the base for injection. The booster injection was inserted at $3 \mathrm{~cm}$ from the base of the tail until the needle tip reached $1.5 \mathrm{~cm}$ from the base (Figure $4 \mathrm{a}$ ). The needle was wiped and inserted bevel up and parallel to the tail in order to prevent leakage of emulsion. We 
a

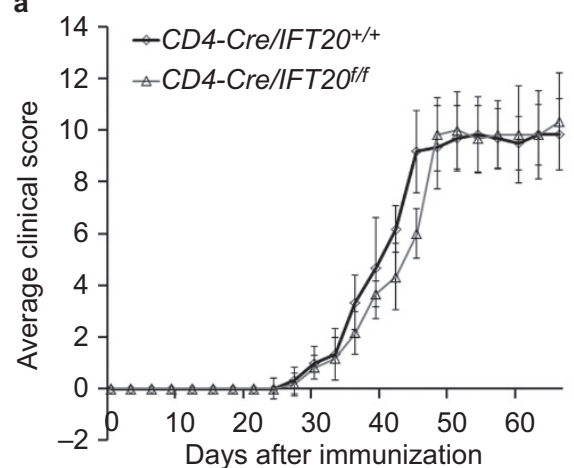

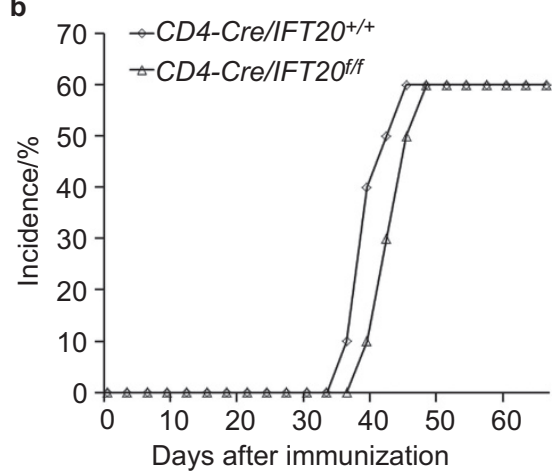

c

d
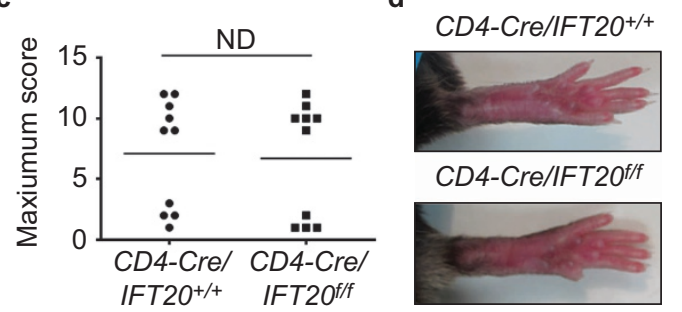

e

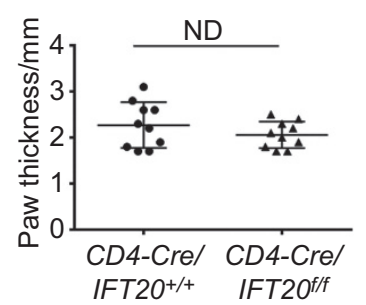

Figure 5. Deletion of IFT20 in more mature T cells had only mild effects on the development of CIA. (a) Mean clinical scores \pm s.d. of arthritis in CD4-Cre/

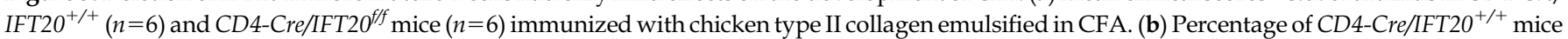
and CD4-Cre/IFT2 $f^{f / f}$ mice that developed arthritis $(n=10)$. (c) The maximum clinical score was recorded until day $66(n=10)$. (d) Hind paws of type II collagen immunized CD4-Cre/IFT20 ${ }^{+/+}$and CD4-Cre/IFT2 $0^{f / f}$ mice. (e) The hind paw thickness was measured at day 66 to indicate arthritis development $(n=10)$. ND indicates no significant difference.

observed arthritis at week 5 after the first immunization. The maximum incidence of arthritis was achieved at 6-7 weeks. To quantitatively evaluate the severity of the arthritis, four paws were observed and measured every 3 days up to 66 days after the first immunization using the grades as described in the section on 'Materials and methods'. The incidence of CIA was significantly lower in the Lck-Cre/ IFT2 $0^{f / f}$ group than that in the LCk-Cre/IFT20 $0^{+/+}$group (Figure 4c). Even during development of the arthritis, the severity of the disease in Lck-Cre/IFT2 $0^{f / f}$ mice was much less than that in LCK-Cre/IFT20 $0^{+/+}$mice (Figure $4 \mathrm{~b}$ and $4 \mathrm{C}$ ). The hind paw of LCK-Cre/IFT20 ${ }^{+/+}$displayed severe joint inflammation evidenced by marked swelling and erythema of paws (Figure 4e). In contrast, Lck-Cre/IFT20 f/f mice were resistant to developing CIA and showed no signs or only slight signs of paw and/or joint swelling (Figure 4e). The thickness of hind paws was measured at the end of the experiment. LCk-Cre/IFT2O $0^{f / f}$ mice had significantly thinner paws than Lck-Cre/IFT20 ${ }^{+/+}$mice, which confirmed that the development and severity of CIA was reduced in Lck-Cre/ IFT2 ${ }^{f / f}$ mice (Figure 4f).

Deletion IFT20 in more mature T cells had only mild effects on the development of $\mathrm{CIA}$

To further determine the role of IFT20 in T cells, CD4-Cre/ IFT2O ${ }^{f / f}$ and CD4-Cre/IFT20 ${ }^{+/+}$mice were subjected to CIA induction. Although CD4-Cre/IFT20 f/f mice showed a delay in the development of arthritis, the incidence of
$\mathrm{CIA}$ was similar in the CD4-Cre/IFT20 f/f group compared to the CD4-Cre//FT20 ${ }^{+/+}$group (Figure $5 \mathrm{~b}$ ). Average clinical scores and maximum scores were not significantly different between CD4-Cre/IFT2 $0^{f / f}$ mice and CD4-Cre/

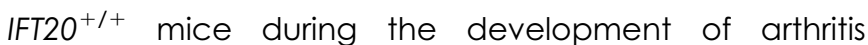
(Figure $5 \mathrm{a}$ and $5 \mathrm{c}$ ). The hind paws of CD4-Cre/IFT20 $0^{+/+}$ mice and CD4-Cre/IFT20 f/f mice displayed swelling and erythema with similar paw thicknesses (Figure $5 d$ and 5 e).

Deletion of IFT20 protected against histopathological progression of arthritis in Lck-Cre/IFT2 $0^{f / f}$ mice, but not in CD4-Cre/IFT20 f/f

In the histological analysis, the affected joints of LCk-Cre/ IFT $2 \mathrm{O}^{+/+}$mice and CD4-Cre/IFT20 ${ }^{+/+}$mice showed typical features of arthritis, characterized by synovial hyperplasia and perivascular infiltration of inflammatory cells. In severely affected joints, there was marked cartilage destruction (Figure 6a and $6 \mathrm{~d}$ ). However, the joints of Lck-Cre/IFT20 f/f mice did not have any significant sign of tissue degeneration or inflammation. In contrast, both CD4-Cre/IFT20 ${ }^{+/+}$and CD4-Cre/IFT20 $0^{f / f}$ mice showed a similar level of joint inflammation and articular cartilage degeneration (Figure 6d). Semiquantitative scoring of these histological parameters confirmed that arthritic severity in CD4-Cre/IFT20 f/f was comparable to that of CD4-Cre/IFT20 ${ }^{+/+}$mice (Figure 6e), whereas Lck-Cre/ IFT20 $0^{f / f}$ mice were strongly protected against CIA histopathology (Figure 6b). 
a

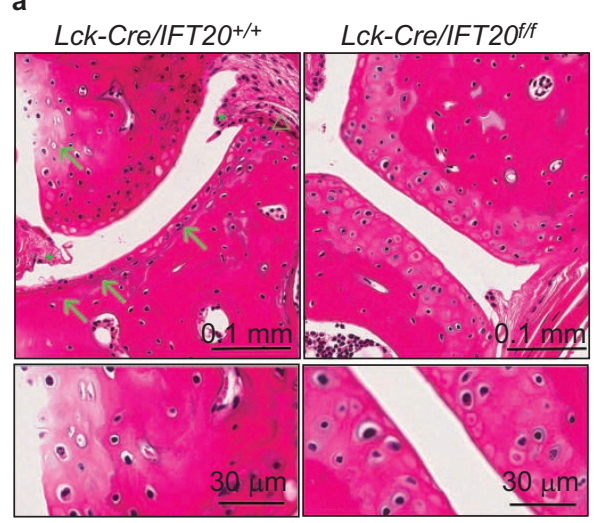

b

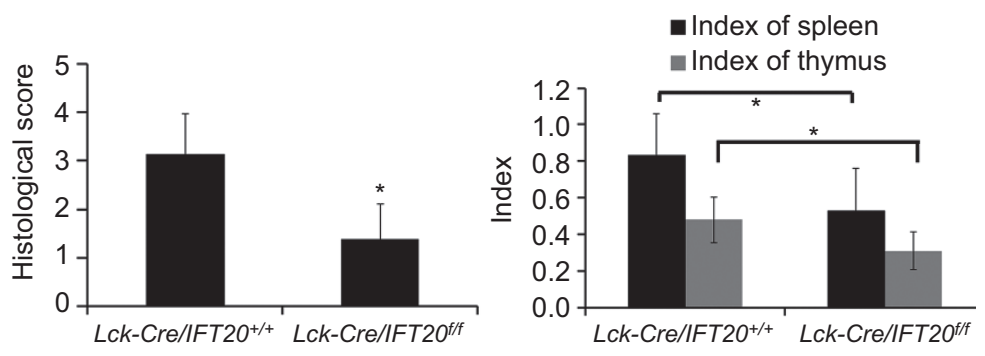

d

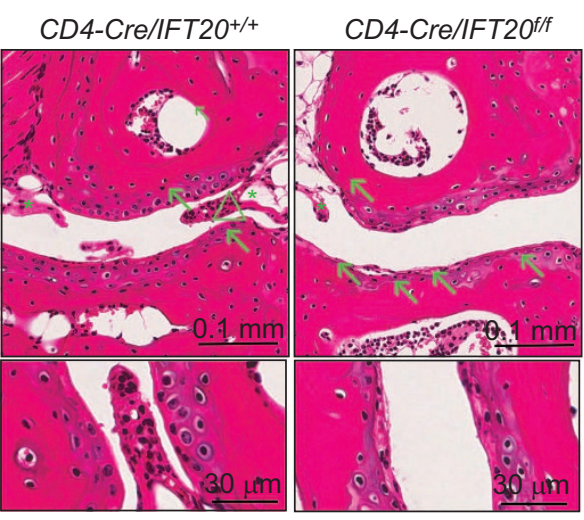

g

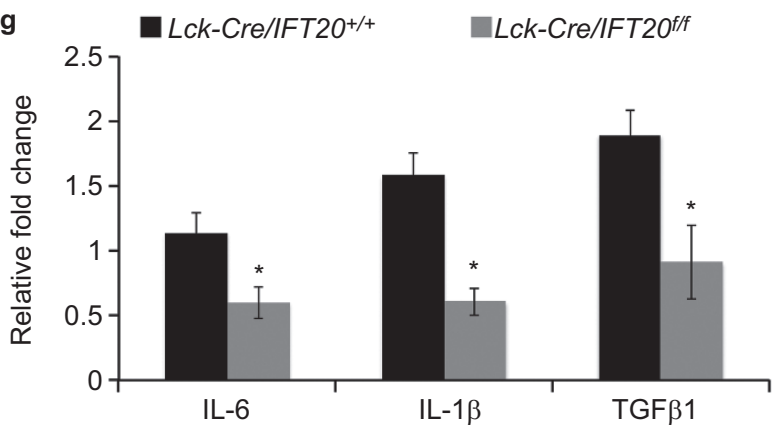

e

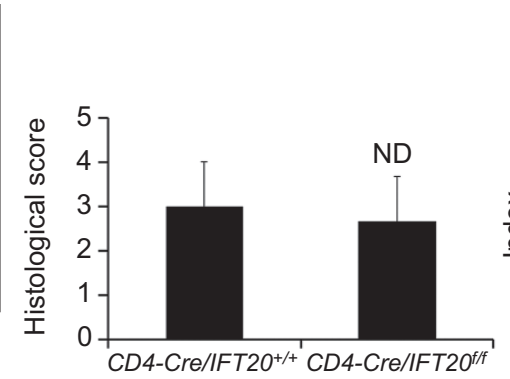

c

f
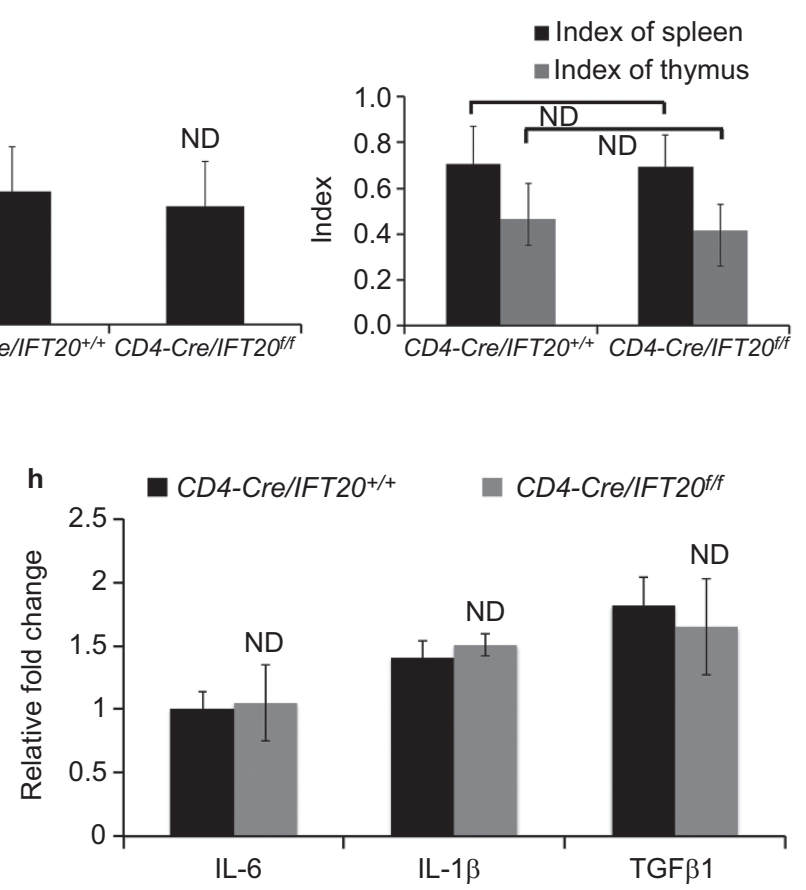

Figure 6. Deletion of IFT20 protected against histopathological progression of arthritis in Lck-Cre/IFT20 f/f mice, but not in CD4-Cre/IFT20 $0^{f / f}$ mice. (a) Representative H\&E-stained section of interphalangeal joints from $L c k-C r e / I F T 20^{+/+}$and $L c k$-Cre/IFT2 $0^{f / f}$ mice. Synovial hyperplasia and pannus formation were inhibited and destruction of articular cartilage was alleviated in $L c k$-Cre/IFT2 $20^{f / f}$ mice. Arrow indicates cartilage destruction; $\Delta$ indicates infiltration of inflammatory cells; * indicates fibrovascular synovial and periarticular proliferation. (b) The histopathological change was scored and data is expressed as mean \pm S.D. for each group of 6 samples $(n=6, P<0.01)$. (c) Indices of thymus and spleen in CIA in $L c k$-Cre/IFT2 $0^{+/+}$and $L c k$-Cre/ IFT2 $0^{f / f}$ mice $(n=8)$. (d) Representative H\&E-stained section of interphalangeal joints from CD4-Cre/IFT20 ${ }^{+/+}$and CD4-Cre/IFT20 $/ f / f$ mice. $(\mathbf{e})$ Histological scores of synovial inflammation and cartilage erosion was shown as mean \pm s.d. $(n=6)$. (f) Indices of thymus and spleen in collageninduced arthritis in CD4-Cre/IFT20 ${ }^{+/+}$and CD4-Cre/IFT20ff mice $(n=8)$. (g) Comparison of IL-1, IL-6 and TGF- $\beta 1$ mRNA levels in the hind paws of LckCre/IFT2 $0^{+/+}$and Lck-Cre/IFT2 $0^{f / f}$ mice $(n=4, P<0.01)$. (h) Comparison of IL-1, IL-6 and TGF- $\beta 1$ mRNA levels in the hind paws of CD4-Cre/IFT2 $0^{+/+}$ and CD4-Cre/IFT2 $f^{f / f}$ mice $(n=4)$. ND indicated no significantly difference. H\&E, hematoxylin and eosin.

The thymus and spleen were weighed to calculate the respective indices at the end of the experiments. Results showed that thymus and spleen indices were higher in Lck-Cre/IFT20 ${ }^{+/+}$mice compared to Lck-Cre/IFT20 f/f mice (Figure 6c). However, these indices were not greatly different in CD4-Cre/IFT20 $/ / f$ mice compared to CD4-Cre/ IFT20 $0^{+/+}$mice (Figure 6f).
To further confirm the degree of inflammation and cartilage degradation of the joint in the CIA mice, we performed the QPCR to detect expression of IL-1 $\beta$, IL-6 and TGF- $\beta 1$ in the paw. IL- $1 \beta$ is a crucial cytokine that mediates both arthritis and cartilage destruction. ${ }^{41} \mathrm{IL}-6$, which participates in the pathogenesis of RA, is the most powerful proinflammatory cytokine. ${ }^{42}$ TGF- $\beta 1$ is highly expressed in the 
later stages of $\mathrm{ClA}^{.43-44}$ Total RNA from the paw was harvested as described in the section on 'Materials and methods'. qPCR results indicated that expression of IL-1 $\beta$, IL-6 and TGF- $\beta 1$ were all significantly lower in the paw of Lck-Cre/ IFT2 ${ }^{f / f}$ mice (Figure 6g). As expected, the expression of IL$1 \beta$, IL-6 and TGF- $\beta 1$ was not significantly different in CD4-Cre/ IFT20 ${ }^{f / f}$ compared to CD4-Cre/IFT20 ${ }^{+/+}$mice (Figure 6h).

\section{DISCUSSION}

IFT proteins are known to form IFT complexes A and B. These proteins interact with other proteins to build cilia and maintain cilia function. ${ }^{45}$ Mutations of IFT or defects in cilia that have been implicated in human disease are called ciliopathies. ${ }^{46-47}$ These effects of these mutations demonstrate the critical role of primary cilia and IFT proteins in organ development and function.

Hematopoietic lineage cells are an exception, however, because they lack cilia. ${ }^{45,48}$ The reason is not yet known. However, Finetti et al. ${ }^{14}$ recently discovered that IFT20 was expressed in both lymphoid and myeloid lineage cells, suggesting a role of IFT proteins beyond cilia development and function. In most eukaryotic cells, IFT20 is localized in cilia, the centrioles, and the Golgi. IFT20 selects and marks vesicles, which contain ciliary proteins, and later assembles these with IFT complexes and transports them within the cilium. ${ }^{49}$ In T lymphocytes, IFT20 is associated with the centriole, Golgi and postGolgi membrane compartments and required for TCR/ CD3 trafficking and immune synapse formation in T lymphocytes in antigen-specific conjugates. ${ }^{14}$ Other IFT proteins, such as IFT88 and IFT57, along with IFT-dependent motor kinesin-2, are also expressed in lymphoid and myeloid cells. ${ }^{14}$ These findings suggest that all or some of the IFT proteins could exist and function in T cells, supporting the theory that the immune synapse may be a type of 'frustrated cilium' and share similar molecular mechanisms. ${ }^{48}$ Immune synapse formation facilitates detailed antigen recognition and effective T-cell responses and, thus, is important for T-cell activation. ${ }^{50-51}$ Knockdown of IFT20 inhibits TCR recycling and disrupts synapse formation in vitro. ${ }^{14}$ However, the role of IFT2O in regulating T-cell development and activation in vivo is largely unknown. Our study, for the first time, analyzed the role of IFT20 in T cells in a mouse CIA model.

In our study, we crossed IFT20 f/f mice with Lck-Cre and CD4-Cre mice to delete IFT20 in the T-cell lineage at early and later stages. Both LCk-Cre and CD4-Cre transgenic lines have been extensively used in the studies of lymphoid progenitors at different developmental stages, ${ }^{38-39}$ which have shown that these lines can delete genes at specific early and later stages of T-cell development. The major stages of T-cell maturation in the thymus are $\mathrm{DN}\left(\mathrm{CD} 4^{-} \mathrm{CD} 8^{-}\right), \mathrm{DP}$ $\left(\mathrm{CD} 4^{+} \mathrm{CD}^{+}\right)$and $\mathrm{SP}\left(\mathrm{CD} 4^{+}\right.$or $\left.\mathrm{CD} 8^{+}\right)$(Figure 1a). Lck-Cre mediated deletion occurs in the DN stage and CD4-Cre targeted deletion begins later in the DP stage. We confirmed that the IFT20 gene was efficiently deleted in both Lck-Cre/ IFT2O ${ }^{f / f}$ and CD4-Cre/IFT2O ${ }^{f / f}$ mice. Both LCk-Cre/IFT20 f/f and CD4-Cre/IFT2 ${ }^{f / f}$ mice were normal and healthy without any significant defects in thymus or spleen size (Figure 2). However, we found deletion of IFT20 with Lck-Cre arrested $T$ cells further along in development than the DP stage (Figure $3 a$ and $3 b$ ). When the cells go through the DN2 to DN4 stages, they express the pre-TCR. Successful pre-TCR expression and translocation to the cell surface is required for DN4 to DP transition. This is called beta-selection. ${ }^{52-53}$ Since IFT20 involvement in transportation is important for the TCR expression, deletion of IFT20 may cause partial impairment of passing beta-selection. Unexpectedly, CD4Cre-mediated IFT20 deletion did not apparently affect DP Tcell differentiation to SP T cells, indicating IFT20 likely does not function or play a minor role in T-cell maturation.

Studies of our CIA mouse models have shown that T-cell activation is important in the initiation and pathogenesis of inflammatory arthritis. ${ }^{54}$ To investigate whether loss of IFT20 in T-cell lineage affects T-cell development and activation, we employed a mouse CIA model in wild-type and IFT20 mutant mice. Chicken type II collagen can activate collagen-specific $T$ cells with the help of antigen-presenting cells, leading the activated $T$ cells to cross-react with and damage the body's own type II collagen through activation of $B$ cells and other immune cells. We found that Lck-Cre/IFT20 f/f mice were resistant to chicken type II collagen-induced arthritis. Lck-Cre/ IFT2 $0^{f / f}$ mice had significantly lower average and maximum clinical arthritis scores, inflammation scores and paw thicknesses compared to Lck-Cre/IFT20 ${ }^{+/+}$mice. This data confirmed that IFT20 deficiency from an early stage of thymocyte differentiation blocked functional Tcell formation and eventually inhibited T-cell response to the collagen challenge. Surprisingly, CD4-Cre/IFT2 $0^{f / f}$ mice had no significant difference from CD4-Cre/IFT20 ${ }^{+/+}$mice in this respect. In addition to the CIA model, we have also challenged Lck-Cre/IFT2 f/f and CD4-Cre/IFT2 ${ }^{f / f}$ mice with Borrelia burgdorferi to induce Lyme disease and associated destructive arthritis. ${ }^{55}$ The role of T cells in development and exacerbation of Lyme disease has been defined. ${ }^{56}$ Consistent with our CIA results, Lck-Cre/IFT2 $0^{f / f}$ mice have less inflammation in paw joints while CD4-Cre/ IFT2 ${ }^{f / f}$ did not display any significant difference from CD4Cre/IFT $20^{+/+}$in response to Borrelia burgdorferi challenge (unpublished data), suggesting IFT20 likely plays a more important role in the early stage of T-cell differentiation. ${ }^{57}$

Cytokines are involved in primary cartilage damage and synovial activation of osteoarthritis. Our data has shown that T cells from CIA models of wild-type and IFT20 mutant mice (Lck-Cre or CD4-Cre) can be subjected to 
antigen-specific (type II collagen) proliferation and cytokine production. ${ }^{58} \mathrm{LL}-1$ is a potent pro-inflammatory cytokine, which is capable of inducing chondrocytes and synovial cells to synthesize the matrix metalloproteinases, which are responsible for the degradation of cartilage. TGF- $\beta$ is well-characterized as a potent chondrocyte growth factor. TGF- $\beta$ not only stimulates de novo matrix synthesis, but also counteracts cartilage degradation by down-regulating IL-1 receptor expression and by increasing both IL-1 receptor antagonist release and the expression of tissue inhibitors of matrix metalloproteinases. IL-6 is the most powerful pro-inflammatory cytokine which participates in the pathogenesis of RA. ${ }^{42}$ By analyzing these cytokines, we found that the expression of IL-1 $\beta$, IL-6 and TGF- $\beta 1$ was significantly decreased in the paw of Lck-Cre/ IFT20 f/f mice (Figure $6 \mathrm{~g}$ ). These finding demonstrate that IFT20 plays crucial role in the early stage of T-cell differentiation and function. In the late stage of T-cell differentiation, IFT20 did not markedly affect T-cell maturation and the response of $T$ cells to type $\|$ collagen antigen. Consistent with these finding, the expression of IL-1 $\beta$, IL-6 and TGF- $\beta$ were not significantly different in CD4-Cre/ IFT20 f/f compared to CD4-Cre/IFT20 ${ }^{+/+}$(Figure 6h). Our in vivo results identify that IFT20 is an important regulator in Tcell early stage differentiation and function and provide the first evidence to implicate IFT20 might be unimportant for late stage of CD4 T-cell maturation and function.

\section{Competing interests}

The authors declare no conflict of interest.

\section{Acknowledgements}

The authors thank Miss Stacy Scheuneman for editing the manuscript, and thank Dr Raymond J. Kelleher, the director of the Flow Cytometry Facility at the School of Medicine and Biomedical Sciences, University at Buffalo, for assistance with the flow cytometry. Research reported in this publication was supported by the National Institute of Arthritis and Musculoskeletal and Skin Diseases, part of the National Institutes of Health, under Award Numbers AR055678, DE023105 and AR061052 to SY. The content is solely the responsibility of the authors and does not necessarily represent the official views of the National Institutes of Health.

\section{References}

1 KozMinski KG, Johnson KA, Forscher P, Rosenbaum JL. A motility in the eukaryotic flagellum unrelated to flagellar beating. Proc Natl Acad Sci USA 1993; 90: 5519-5523.

2 Rosenbaum JL, Witman GB. Intraflagellar transport. Nat Rev Mol Cell Biol 2002; 3: 813-825.

3 Taschner M, Bhogaraju S, Lorentzen E. Architecture and function of IFT complex proteins in ciliogenesis. Differentiation 2012; 83: S12-S22.

4 Cole DG, Diener DR, Himelblau AL, Beech PL, Fuster JC, Rosenbaum JL. Chlamydomonas kinesin-II-dependent intraflagellar transport (IFT): IFT particles contain proteins required for ciliary assembly in Caenorhabditis elegans sensory neurons. J Cell Biol 1998; 141: 993-1008.

5 Cole DG, Snell WJ. SnapShot: intraflagellar transport. Cell 2009; 137: 784-784.e1.
6 Piperno G, Siuda E, Henderson S, Segil M, Vaananen H, Sassaroli M. Distinct mutants of retrograde intraflagellar transport (IFT) share similar morphological and molecular defects. J Cell Biol 1998; 143: 1591-1601.

7 Ishikawa H, Marshall WF. Ciliogenesis: building the cell's antenna. Nat Rev Mol Cell Biol 2011; 12: 222-234.

8 Pedersen LB, Rosenbaum JL. Intraflagellar transport (IFT) role in ciliary assembly, resorption and signalling. Curr Top Dev Biol 2008; 85: 23-61.

9 Orozco JT, Wedaman KP, Signor D, Brown H, Rose L, Scholey JM. Movement of motor and cargo along cilia. Nature 1999; 398: 674.

10 Follit JA, San Agustin JT, Xu F et al. The Golgin GMAP210/TRIP11 anchors IFT20 to the Golgi complex. PLoS Genet 2008; 4: e1000315.

11 Follit JA, Tuft RA, Fogarty KE, Pazour GJ. The intraflagellar transport protein IFT20 is associated with the Golgi complex and is required for cilia assembly. Mol Biol Cell 2006; 17: 3781-3792.

12 Baker SA, Freeman K, Luby-Phelps K, Pazour GJ, Besharse JC. IFT20 links kinesin II with a mammalian intraflagellar transport complex that is conserved in motile flagella and sensory cilia. J Biol Chem 2003; 278: 34211-34218.

13 Cesari F. Membrane trafficking: IFT proteins play a new game. Nat Rev Mol Cell Biol 2009; 10: 812.

14 Finetti F, Paccani SR, Riparbelli MG et al. Intraflagellar transport is required for polarized recycling of the TCR/CD3 complex to the immune synapse. Nat Cell Biol 2009; 11: 1332-1339.

15 Jonassen JA, San Agustin J, Follit JA, Pazour GJ. Deletion of IFT20 in the mouse kidney causes misorientation of the mitotic spindle and cystic kidney disease. J Cell Biol 2008; 183: 377-384.

16 Keady BT, Le YZ, Pazour GJ. IFT20 is required for opsin trafficking and photoreceptor outer segment development. Mol Biol Cell 2011; 22: 921930.

17 McInnes IB, Schett G. The pathogenesis of rheumatoid arthritis. N Engl J Med 2011; 365: 2205-2219.

18 Brand DD, Latham KA, Rosloniec EF. Collagen-induced arthritis. Nat Protoc 2007; 2: 1269-1275.

19 Brand DD. Rodent models of rheumatoid arthritis. Comp Med 2005; 55: 114-122.

20 Asquith DL, Miller AM, McInnes IB, Liew FY. Animal models of rheumatoid arthritis. Eur J Immunol 2009; 39: 2040-2044.

21 Inglis JJ, Criado G, Medghalchi M et al. Collagen-induced arthritis in C57BL/6 mice is associated with a robust and sustained T-cell response to type II collagen. Arthritis Res Ther 2007; 9: R113.

22 Seetharaman R, Mora AL, Nabozny G, Boothby M, Chen J. Essential role of $\mathrm{T}$ cell NF- $\mathrm{KB}$ activation in collagen-induced arthritis. J Immunol 1999; 163: 1577-1583.

23 Nakahama T, Kimura A, Nguyen NT et al. Aryl hydrocarbon receptor deficiency in $\mathrm{T}$ cells suppresses the development of collagen-induced arthritis. Proc Natl Acad Sci USA 2011; 108: 14222-14227.

24 Chung SH, Seki K, Choi BI et al. CXC chemokine receptor 4 expressed in T cells plays an important role in the development of collagen-induced arthritis. Arthritis Res Ther 2010; 12: R188.

25 Jonassen JA, San Agustin J, Follit JA, Pazour GJ. Deletion of IFT20 in the mouse kidney causes misorientation of the mitotic spindle and cystic kidney disease. J Cell Biol 2008; 183: 377-384.

26 Yang S, Li YP, Liu T et al. Mx1-Cre mediated Rgs12 conditional knockout mice exhibit increased bone mass phenotype. Genesis 2013; 51: 201-209.

27 Campbell IK, Hamilton JA, Wicks IP. Collagen-induced arthritis in C57BL/ 6 (H-2b) mice: new insights into an important disease model of rheumatoid arthritis. Eur J Immunol 2000; 30: 1568-1575.

28 Liu Y, Zhang L, Wu Y et al. Therapeutic effects of TACI-Ig on collageninduced arthritis by regulating $\mathrm{T}$ and $\mathrm{B}$ lymphocytes function in DBA/1 mice. Eur J Pharmacol 2011; 654: 304-314. 
29 Taneja V, Taneja N, Paisansinsup T et al. CD4 and CD8 T cells in susceptibility/protection to collagen-induced arthritis in HLA-DQ8transgenic mice: implications for rheumatoid arthritis. J Immunol 2002; 168: 5867-5875.

30 Kwon OG, Ku SK, An HD, Lee YJ. The Effects of Platycodin D, a Saponin Purified from Platycodi Radix, on Collagen-Induced DBA/1J Mouse Rheumatoid Arthritis. Evid Based Complement Alternat Med 2014; 2014: 954508.

31 Liu Y, Zhang L, Wu Y et al. Therapeutic effects of TACI-Ig on collageninduced arthritis by regulating $\mathrm{T}$ and $\mathrm{B}$ lymphocytes function in DBA/1 mice. Eur J Pharmacol 2011; 654: 304-314.

32 Tong T, Zhao W, Wu YQ et al. Chicken type II collagen induced immune balance of main subtype of helper $\mathrm{T}$ cells in mesenteric lymph node lymphocytes in rats with collagen-induced arthritis. Inflamm Res 2010; 59: 369-377.

33 Zhang LL, Wei W, Yan SX, Hu XY, Sun WY. Therapeutic effects of glucosides of Cheanomeles speciosa on collagen-induced arthritis in mice. Acta Pharmacol Sin 2004; 25: 1495-1501.

34 Stordeur P, Poulin LF, Craciun L et al. Cytokine mRNA quantification by real-time PCR. J Immunol Methods 2002; 259: 55-64.

35 Hochrainer K, Racchumi G, Anrather J. Site-specific phosphorylation of the p65 protein subunit mediates selective gene expression by differential NF-KB and RNA polymerase II promoter recruitment. J Biol Chem 2013; 288: 285-293.

36 Chu CY, Peng FC, Chiu YF et al. Nanohybrids of silver particles immobilized on silicate platelet for infected wound healing. PLoS One 2012; 7: e38360.

37 Kisielow P, von Boehmer H. Development and selection of T cells: facts and puzzles. Adv Immunol 1995; 58: 87-209.

38 Lee PP, Fitzpatrick DR, Beard C et al. A critical role for Dnmt1 and DNA methylation in T cell development, function, and survival. Immunity 2001; 15: 763-774.

39 Shi J, Petrie HT. Activation kinetics and off-target effects of thymusinitiated cre transgenes. PLoS One 2012; 7: e46590.

40 Guedez YB, Whittington KB, Clayton JL et al. Genetic ablation of interferon-gamma up-regulates interleukin-1beta expression and enables the elicitation of collagen-induced arthritis in a nonsusceptible mouse strain. Arthritis Rheum 2001; 44: 2413-2424.

41 Lubberts E, van den Berg WB. Cytokines in the pathogenesis of rheumatoid arthritis and collagen-induced arthritis. Adv Exp Med Biol 2003; 520: 194-202.

42 Yusof MYM, Emery P. Targeting interleukin-6 in rheumatoid arthritis. Drugs 2013; 73: 341-356.

43 Marinova-Mutafchieva L, Gabay C, Funa K, Williams R. Remission of collagen-induced arthritis is associated with high levels of transforming growth factor- $\beta$ expression in the joint. Clin Exp Immunol 2006; 146: 287-293.

44 Thornton S, Duwel LE, Boivin GP, Ma Y, Hirsch R. Association of the course of collagen-induced arthritis with distinct patterns of cytokine and chemokine messenger RNA expression. Arthritis Rheum 1999; 42: 11091118.

45 Pazour GJ, Witman GB. The vertebrate primary cilium is a sensory organelle. Curr Opin Cell Biol 2003; 15: 105-110.

46 Eggenschwiler JT, Anderson KV. Cilia and developmental signaling. Annu Rev Cell Dev Biol 2007; 23: 345-373.

47 Goetz SC, Anderson KV. The primary cilium: a signalling centre during vertebrate development. Nat Rev Genet 2010; 11: 331-344.

48 Finetti F, Paccani SR, Rosenbaum J, Baldari CT. Intraflagellar transport: a new player at the immune synapse. Trends Immunol 2011; 32: 139145.

49 Nachury MV, Seeley ES, Jin H. Trafficking to the ciliary membrane: how to get across the periciliary diffusion barrier? Annu Rev Cell Dev Biol 2010; 26: 59-87.

50 Grakoui A, Bromley SK, Sumen C et al. The immunological synapse: a molecular machine controlling T cell activation. Science 1999; 285: 221227.

51 Dustin ML, Chakraborty AK, Shaw AS. Understanding the structure and function of the immunological synapse. Cold Spring Harb Perspect Biol. 2010 Oct; 2(10): a002311.

52 Germain RN. T-cell development and the CD4-CD8 lineage decision. Nat Rev Immunol 2002; 2: 309-322.

53 Hernandez JB, Newton RH, Walsh CM. Life and death in the thymuscell death signaling during T cell development. Curr Opin Cell Biol 2010; 22: 865-871.

54 Tran CN, Lundy SK, Fox DA. Synovial biology and T cells in rheumatoid arthritis. Pathophysiology 2005; 12: 183-189.

55 Sze CW, Zhang K, Kariu T, Pal U, Li C. Borrelia burgdorferi needs chemotaxis to establish infection in mammals and to accomplish its enzootic cycle. Infect Immun 2012; 80: 2485-2492.

56 McKisic MD, Redmond WL, Barthold SW. Cutting edge: T cell-mediated pathology in murine Lyme borreliosis. J Immunol 2000; 164: 6096-6099.

57 Onoyama I, Tsunematsu R, Matsumoto A et al. Conditional inactivation of Fbxw7 impairs cell-cycle exit during T cell differentiation and results in lymphomatogenesis. J Exp Med 2007; 204: 2875-2888.

58 Ellebedy AH, Lupfer C, Ghoneim HE, DeBeauchamp J, Kanneganti TD, Webby RJ. Inflammasome-independent role of the apoptosis-associated speck-like protein containing CARD (ASC) in the adjuvant effect of MF59. Proc Natl Acad Sci U S A 2011; 108: 2927-2932.

(c) (1) (2) This work is licensed under a Creative Commons Attribution(1) No sA NonCommercial-ShareAlike 3.0 Unported License. The images or other third party material in this article are included in the article's Creative Commons license, unless indicated otherwise in the credit line; if the material is not included under the Creative Commons license, users will need to obtain permission from the license holder to reproduce the material. To view a copy of this license, visit http://creativecommons.org/licenses/by-nc-sa/3.0/ 